Working Paper 06-10

Economics Series 02

January 2006
Departamento de Economía

Universidad Carlos III de Madrid

Calle Madrid, 126

28903 Getafe (Spain)

Fax (34) 916249875

\title{
MIDDLEMEN: THE VISIBLE MARKET MAKERS *
}

Makoto Watanabe ${ }^{1}$

\begin{abstract}
This paper presents a search-theoretic model where middlemen can emerge endogenously to intermediate between ex ante homogeneous buyers and sellers in the presence of coordination frictions. Middlemen set price to compete in the market, and hold an inventory to provide a high matching service. I show that middlemen's inventories can mitigate trade imbalances and interact with price competition, generating an interesting tradeoff for the equilibrium price determination. The competitive limit emerges when middlemen guarantee excess demand will never occur. Conditions are characterized under which middlemen carry out the short-side principle for the market price to be Walrasian.
\end{abstract}

JEL Classification: D4, D5, D6, D8, G2, L1

Keywords: Intermediation, Competitive Search Equilibrium, Urn-ball Matching Models, Inventory Holdings

*Acknowledgements: I am indebted to V. Bhaskar, Kenneth Burdett, and Melvyn G. Coles, for their insightful comments and suggestions. I am also grateful to Kenn Ariga, Gianni De Fraja, Peiter Gautier, Belen Jerez, Seongman Moon, Pierre Regibeau, Eric Smith, Serene Tan, Randy Wright, and seminar and conference participants at Amsterdam, Carlos III, Econometric Society World Congress 2005, Essex, Fukuoka, Hitotsubashi, Japanese Economic Association meeting, Kansai, Kyoto, Leicester, Maastricht, Osaka, Tokyo, and Waseda for providing helpful discussion on earlier drafts. I appreciate Nico Temme for his guidance about uniform asymptotic expansions of the incomplete gamma functions. Of course, any remaining errors are my own.

\footnotetext{
${ }^{1}$ Department of Economics. Universidad Carlos III de Madrid, Calle Madrid, 12628903 Getafe (Madrid).

E-mail: mwatanb@eco.uc3m.es
} 


\section{Introduction}

It has long been known that in a competitive market for a homogeneous good, price adjusts itself to resolve trade imbalances where demand and supply meet. In most real-life markets however, a gap exists between production and consumption. In most retail markets, consumers obtain a significant proportion of products at cost from intermediaries, who are prepared to buy and sell and define the price to match purchases to sales. ${ }^{1}$ Although the role of middlemen to mitigate market frictions is familiar, the functioning of markets that middlemen provide has not been given the attention it deserves. The quest for a satisfactory description of "how markets do operate" hinges on the story about the role middlemen play in the process of price formation and resource allocations.

The objective of this paper is to look inside the black box that justifies the very existence of middlemen. In their seminal work, Rubinstein and Wolinsky (1987) propose that intermediaries can be active when having a higher matching rate than producers and consumers, while Spulber (1996) suggests that intermediaries can exist with price competition. Not only are these roles of middlemen interrelated with each other, but also are linked tightly to their market making activities. Particularly important among middlemen's market makings are inventory holdings that provide their customers with a high matching service and promote competition to improve resource allocations. The present paper proposes a unified framework in which middlemen, like supermarkets, emerge to (1) link producers and consumers, (2) set price for competition, and (3) hold inventories to smooth trade imbalances among producers and consumers.

Consider the following competitive search equilibrium framework where each period consists of two sub-periods, day and night, and where a separate market is open for each sub-period. ${ }^{2}$ Every day, sellers produce one unit of a homogeneous good, e.g. a potato, while buyers wish to consume one unit of that good. The day-markets are retail markets which I assume to be frictional. In other words, the buyer-seller trades at day-markets are on an uncoordinated basis, so that both buyers and sellers face the possibility of being rationed every day.

Once the day-market closes, the night-market opens. The night-markets are wholesale markets. Following Lagos and Wright (2005), I assume the night-markets to be frictionless. Middlemen emerge

\footnotetext{
${ }^{1}$ Burstein, Neves, and Rebelo (2003) document that distribution costs represent more than $40 \%$ of the retail price for the average consumption goods in the US. Spulber (1999) estimates market-based activities, fundamentally different from production activities, contribute at least $28 \%$ of US GDP.

${ }^{2}$ Unlike the traditional random matching approach, the competitive search equilibrium incorporates price competition and directed search. See Accemoglu and Shimer (1999a,b), Moen (1997), Mortensen and Wright (2002), Shi (2002b), Shimer (1996), and Shimer (2005). The day-night trading-period structure is proposed in a monetary model of Lagos and Wright (2005) and Rocheteau and Wright (2005).
} 
with storage technology to purchase potatoes from the sellers, who have failed to sell it during the day. They store the potatoes as an inventory at night and stand ready for buyers at day.

The notion of the day-market frictions I employ follows from the directed matching literature developed by Peters (1991), Montogomery (1991), and Burdett, Shi and Wright (2001). Specifically, I assume buyers cannot coordinate their actions over which seller to visit. Since more than one buyer may happen to visit a particular seller, buyers face the risk of being unable to purchase. At the same time, because no buyer may show up, sellers face the risk of being unable to sell the potato. Under these frictions, middlemen's inventories imply availability of goods to buyers who prefer a higher matching rate at a price. A tradeoff exists for buyers between the rate of being served and the price.

The day-market equilibrium is constructed in Section 2. I show middlemen's inventories generate two important effects on the day-market outcome. On the one hand, middlemen's capacity advantage provides better service and thus creates a demand-stimulating effect to attract a larger number of buyers. This effect gives middlemen a monopoly power for all units of their goods, and increases the price. On the other hand, as their inventories increase, it is less likely that excess demand occurs at each individual middleman. This effect decreases the price, since an increased risk of not selling out the inventory weakens the middlemen's bargaining position against buyers over trading surplus for each unit of the goods. ${ }^{3}$ Although the combined effects are in general uneven, the latter effect becomes dominant when inventories become sufficiently large so that prices become more competitive.

To endogenize middlemen's inventory restocking, Section 3 builds a steady-state equilibrium onto the day-market equilibrium. Given a finite number of potatoes, each middleman can restock more inventories when fewer middlemen are operating in the steady-state equilibrium. When there is an aggregate excess supply within this framework, I show that the steady-state equilibrium is competitive in the limit as proportion of middlemen is sufficiently small. Given each middleman restocks a sufficiently large inventory at night, the middlemen's inventory wipes off the buyer-seller direct trades in the day-market. In other words, the demand effect of the middlemen's inventory determines the day-market equilibrium allocations such that the probability that each individual supplier (either a seller or middleman) receives fewer buyers than the capacity approaches to one in the competitive limit. At the same time, the bargaining effect determines the day-market equilibrium prices such that the proportion of trading surplus that any given buyer obtains from each given middleman approaches to one. The result essentially claims that under the aggregate excess supply, the demand

\footnotetext{
${ }^{3}$ The former effect features that big supermarkets attract more customers than small shops do, while the latter features that retailers often have a sale when holding many inventories implies a high risk.
} 
side of the market can be cleared out endogenously in the competitive limit. ${ }^{4}$ Middlemen can resolve trade imbalances that coordination frictions among buyers inject into the market.

Before closing this introductory section, it is worth emphasizing that the present paper considers the key functions of middlemen that are studied separately in the literature. One approach is used in Rubinstein and Wolinsky (1987), Li (1998), and Shevichenko (2004) which emphasizes a middlemen's high matching rate, but do not consider price competition among middlemen. In the other approach used in Spulber (1996) and Rust and Hall (2003), price competition is emphasized as the middlemen's main role of market-makings, but the matching function is exogenous. In my paper, the competitive search equilibrium enables price competition among middlemen to play the role for intermediation. At the same time, the underlying directed matching structure that I propose can provide a natural endogenous link between inventory holdings and a high matching rate that middlemen provide to buyers. ${ }^{5}$ This new approach provides a richer understanding of middlemen as well as gives novel insights into the price formation that are missing in the literature. I will discuss empirical implications of the present model and the related literature in more detail in Section 4. Section 5 concludes. All proofs are contained in the Appendix.

\section{Day market}

\section{$2.1 \quad$ Environment}

Consider an economy where there are three types of agents: buyers, sellers and middlemen that are all continuum measured by one, $S$, and $M$ respectively. Index $s$ or $m$ refers to a supplier whose name is seller or middleman while index $b$ refers to a buyer. Time is discrete and continues forever. Each period is divided into two sub-periods - a day and a night. At the beginning of any day each seller has one unit of the goods for sale and each middleman has $I$ units of the goods. All buyers wish to purchase a unit of the good each day. The goods are homogeneous and non-durable. Before the day starts, each seller and middleman post a price they are willing to sell at. When the day starts buyers observe all prices and decide which supplier to visit. A buyer can visit only one seller, or one middleman. Given the number of buyers who show up, the seller or middleman sells the good, or goods, at the price stated. If there are more buyers than goods available, any buyer purchases the

\footnotetext{
${ }^{4}$ The reverse logic should also apply to generate the opposite outcome: Under the aggregate excess demand, the supply side of the market can be cleared out in the monopoly limit. To confirm this intuition, it is also shown that the market price that middlemen set can be Walraisan if sellers are not operating in the day-market.

${ }^{5}$ Shevichenko provides an interesting inventory-based random matching model for middlemen. I will discuss his model in Section 4.
} 
good with equal probability. Buyers who purchase at price $p$, obtain period utility $1-p$, whereas those who do not purchase obtain period utility 0 . Any supplier who sells $z$ units of the good at price $p$ obtains profit $z p$ per period. The period is then repeated infinitely. For simplicity I assume zero rate of all agents' intertemporal preference. How the sellers and middlemen obtain the goods, they supply in each day market will be discussed in the following section when the night-market is described.

In this section, I focus my attention on the price-posting game in the day-market. The model generalizes the standard directed matching model to allow for multiple capacities $k \geq 1$ where $k$ is any positive integer. Essentially, environments in the day-markets are the same as in Burdett, Shi, and Wright (2001) and Shi (2002a) although they study the case with $k=2$. In the first stage, each supplier selects s price simultaneously, given the capacity. Observing all prices and capacities, buyers assign a visiting probability to each supplier in the second stage. Then, the good or the goods are allocated depending on the capacity and the number of buyers who visit the given supplier. Assuming buyers cannot coordinate their actions over which suppliers to visit, implies that I focus my attention on a symmetric equilibrium in which buyers randomize their visiting strategies in the second stage. The randomness injected by buyers' mixing strategies allows for some buyers obtain a good successfully and others not in equilibrium. The mixing equilibrium in the second stage provides a reasonable description of a large game that captures coordination frictions among buyers. This is commonly employed in the directed matching literature. ${ }^{6}$

In what follows, I construct a symmetric steady-state equilibrium in the day-market that has the following characteristics: (a) All middlemen offer the identical price, $p_{m}$, expecting to attract the identical number of buyers $x_{m}$, and all sellers offer the identical price, $p_{s}$, expecting the identical number of buyers $x_{s} ; 7^{7}$ (b) Buyers use identical mixed strategies. They visit some seller with probability $S x_{s}$ with assigning an equal probability to each seller, and visit some middleman with probability $M x_{m}$ with assigning an equal probability to each middleman. The buyers' visiting probabilities satisfy the adding-up restriction,

$$
M x_{m}+S x_{s}=1
$$

(c) Sellers' and middlemen's price postings are optimal given others' price offers and buyers' visiting strategies. Buyers' visiting strategies are optimal given the prices posted by sellers and middlemen and all other buyers' visiting strategies; (d) Agents' expectations are rational.

\footnotetext{
${ }^{6}$ See Burdett, Shi, and Wright (2001) for more discussions on this issue.

${ }^{7}$ Coles and Eeckhout (2003) considers a more general setting in which sellers are allowed to offer a trading mechanism that is contingent on the ex post number of buyers appearing. However, they show that there is always an equilibrium in which firms' price posting strategies are not contingent on the ex post number of buyers, which I employ here.
} 


\subsection{Buyers' directed search}

Assuming for the moment the existence of a symmetric equilibrium, I shall begin with the matching probability. The underlying matching environment is described as follows. Suppose a buyer visits a particular seller who holds one unit for a sale and $n_{s}$ other buyers also visit that seller. In this case the buyer purchases the good with probability $1 /\left(n_{s}+1\right)$. Suppose now a buyer visits a middleman who holds $I$ units and $n_{m}$ others also visit that middleman. If $n_{m} \geq I$, the buyer purchases from this middleman with probability $I /\left(n_{m}+1\right)$. Otherwise, the buyer obtains the good with probability one.

The following lemma shows that the probability that any given buyer is served when visiting a supplier $i$ can be expressed in terms of the expected number of buyers at that supplier $i\left(x_{i}>0\right)$ and the number of goods available $(k \geq 1)$. I denote this probability as $\eta^{i}=\eta^{i}\left(x_{i}, k\right) .^{8}$

Lemma 1 Given $x_{i}>0$ and $k \geq 1$, the buyers' probability of obtaining a good from supplier $i$ who holds $k$ units of goods for sales is given by the following closed form expression:

$$
\eta^{i}=\frac{\Gamma\left(k, x_{i}\right)}{\Gamma(k)}+\frac{k}{x_{i}}\left(1-\frac{\Gamma\left(k+1, x_{i}\right)}{\Gamma(k+1)}\right) .
$$

Further, $\eta^{i}$ satisfies the following properties: ${ }^{9}$

- $\eta^{i}$ is strictly decreasing in $x_{i}$ and satisfies $\lim \eta^{i}\left(x_{i}, k\right)=1$ as $x_{i} \rightarrow 0$ and $\lim \eta^{i}\left(x_{i}, k\right)=0$ as $x_{i} \rightarrow \infty$, given $1 \leq k<\infty$.

- $\eta^{i}$ is strictly increasing in $k$ and satisfies $\eta^{i}\left(x_{i}, 1\right)=\left(1-e^{-x_{i}}\right) / x_{i}$ and $\lim \eta^{i}\left(x_{i}, k\right)=1$ as $k \rightarrow \infty$, given $0<x_{i}<\infty$.

To illustrate how the service probability $\eta^{i}$ for a given buyer in Lemma 1 can be interpreted, let $X_{O}$ denote a random variable representing the number of the other buyers appearing at supplier $i$. Given continuum of agents, buyers arrive at a Poisson rate $\frac{x^{n} e^{-x}}{n !}$ with mean $x=x_{i}$, where $n=n_{i}$ represents the realized number of buyers at supplier $i$. As mentioned above, the service probability from supplier $i$ can be decomposed into two parts depending on the possibility of whether stockouts occur or not.

\footnotetext{
${ }^{8}$ This probability generalizes the standard urn-ball matching probability to allow for multiple 'urns' (capacities). An economic application of urn-ball models dates back to Butters (1977). Albrecht, Gautier, Tan and Vroman (2003) extends the standard urn-ball formula in the opposite direction to my generalization, by allowing for multiple 'balls' (applications) in a labor market context.

${ }^{9} \Gamma(k)=(k-1) !=\int_{0}^{\infty} t^{k-1} e^{-t} d t$ is the gamma function and $\Gamma(k, x)=\int_{x}^{\infty} t^{k-1} e^{-t} d t$ is the incomplete gamma function.
} 


$$
\begin{aligned}
\eta^{i}= & \operatorname{Prob}\left(X_{O}<k\right) \operatorname{Prob}\left(\text { served } \mid X_{O}<k\right)+\operatorname{Prob}\left(X_{O} \geq k\right) \operatorname{Prob}\left(\text { served } \mid X_{O} \geq k\right) \\
= & \left\{\operatorname{Prob}\left(X_{O}=0\right)+\operatorname{Prob}\left(X_{O}=1\right)+\ldots \ldots+\operatorname{Prob}\left(X_{O}=k-1\right)\right\} \\
& \quad+\left\{\operatorname{Prob}\left(X_{O}=k\right) \frac{k}{k+1}+\operatorname{Prob}\left(X_{O}=k+1\right) \frac{k}{k+2}+\ldots \ldots\right\} .
\end{aligned}
$$

In the above equation, the terms in the first bracket represent the service probability when there are $n_{i}=\{0,1,2,3, \ldots, k-1\}$ other buyers at supplier $i$. In these cases, a given buyer will get served with probability one if she/he visits the supplier $i$. The terms in the second bracket represent the service probability when there are $n_{i}=\{k, k+1, k+2, \ldots\}$ other buyers appearing at the given supplier $i$. In these cases, stockouts occur and the given buyer is selected with probability $k /\left(n_{i}+1\right)$. In sum, these two objects constitute the overall service probability for a given buyer. By applying the Poisson density to the buyers' arrival rate, Lemma 1 establishes the closed form expression as follows: ${ }^{10}$

$$
\begin{aligned}
\eta^{i} & =\left\{e^{-x_{i}}+x_{i} e^{-x_{i}}+\ldots \ldots+\frac{x_{i}^{k-1} e^{-x_{i}}}{(k-1) !}\right\}+\left\{\frac{x_{i}^{k} e^{-x_{i}}}{k !} \frac{k}{k+1}+\frac{x_{i}^{k+1} e^{-x_{i}}}{(k+1) !} \frac{k}{k+2}+\ldots \ldots\right\} \\
& =\frac{\Gamma\left(k, x_{i}\right)}{\Gamma(k)}+\frac{k}{x_{i}}\left(1-\frac{\Gamma\left(k+1, x_{i}\right)}{\Gamma(k+1)}\right) .
\end{aligned}
$$

The terms in the first bracket (in the first line equation above) are summed to $\Gamma\left(k, x_{i}\right) / \Gamma(k)$ that represents the service probability for no stockout cases. Similarly, the terms in the second bracket represent the service probability for stockout cases. ${ }^{11}$ Details for its derivation are in the proof of Lemma 1. Clearly, the greater the expected number of buyers appearing at the given supplier, the smaller the probability that a given buyer gets served if she/he visits the supplier. Hence, $\eta^{i}$ is strictly decreasing in $x_{i}$ given $k$. Similarly, a larger capacity implies a higher service, hence $\eta^{i}$ is strictly increasing in $k$ given $x_{i}$. The standard urn-ball matching function that is often used in the directed matching literature corresponds to the case where $k=1$.

Given the service probability stated above and prices, a symmetric equilibrium requires that buyers are indifferent of visiting any supplier. To characterize the mixing equilibrium in the buyers' visiting stage, consider a situation where a supplier $(i)$ (or a deviator $(i)$ ) sets a price $p_{(i)}$. Suppose now that all agents believe the supplier $(i)$ would attract $x_{(i)}$ buyers on average. The objective here is to

\footnotetext{
${ }^{10}$ In the standard urn-ball matching model with single urn, the probability of this event is binomial under finite agents and is approximated by a Poisson point process under continuum agents. In my situation with multiple capacity and continuum agents, it follows from a Poisson counting process. For reference to the Poisson counting process, see Taylor and Karlin (1998) p.185-189, for example. Additional Appendix shows that the service probability stated in Lemma 1 is the limit of the one constructed under finite agents setup counterpart as the number of agents gets large.

${ }^{11}$ From the standpoint of a given buyer, $1-\Gamma(k+1, x) / \Gamma(k+1)$ represents the probability that more than or equal to $k+1$ other buyers appear at the supplier $i$. The term $k / x$ reflects the nature of urn-ball matching process in which $k$ buyers are selected randomly from among those at hand.
} 
characterize the mixing equilibrium that determines $x_{(i)}$ for a price $p_{(i)}$. Given their belief and the service probability, $x_{(i)}$ is determined to reflect buyers' mixing strategies each period in equilibrium.

Let $V^{b}$ represent the per-period expected utility that buyers obtain by choosing the best offer in the day-market. Note that as the supplier $(i)$ is infinitesimal, its price offer cannot affect this value. If the supplier $(i)$ attracts a positive number of buyers at some period, then in equilibrium any given buyer must be indifferent between choosing $(i)$ and $V^{b}$ at that period. In other words, if a particular buyer assigns a positive visiting probability to $p_{(i)}$ in equilibrium, then it must reflect her/his expectation that the supplier $(i)$ would receive $x_{(i)}$ buyers on average, and she/he would obtain the good with probability $0<\eta^{i}\left(x_{(i)}, k\right)<1$ from the supplier $(i)$. At the same time, all the other buyers have the same expectation. That is, in a symmetric equilibrium, $0<x_{(i)}<\infty$ satisfies:

$$
V^{b}=\eta^{i}\left(x_{(i)}, k\right)\left(1-p_{(i)}\right) \text {. }
$$

Equation (2) is an implicit equation to determine $0<x_{(i)}<\infty$ as a function of $p_{(i)}$ and $k$ that determines the second stage equilibrium, conditioned on values of $V^{b}$. Alternatively, if the supplier (i) attracts no buyers, then it implies in equilibrium that its price is set so high that all buyers are better off by visiting the best alternative supplier, that is, $V^{b}>1-p_{(i)}$ holds in this case. ${ }^{12}$

I will refer to $x_{(i)}$ determined in equation (2) as an expected demand, since all anticipate that $x_{(i)}$ consumers are willing to purchase at a price $p_{(i)}$, given values of $V^{b}$ and $k$. It is readily shown from equation (2) that $x_{(i)}$ is strictly decreasing in $p_{(i)}$, reflecting the buyers' trade-off between the price and the probability of service. Note that ex-ante optimality describing an expect demand must be consistent with the ex-post gains to be realized in equilibrium where agents' expectation becomes self-fulfilling. Such a consistency will be made clear when defining equilibrium. At this stage, however, it is sufficient to keep in mind that $x_{(i)}$ is conditioned on given values of $V^{b}$.

\subsection{Optimal pricing}

Given the buyers' directed search embodied in expected demand, there is price competition among suppliers in equilibrium. At the start of each period, each middleman owns $I$ units of goods and each seller owns one unit of the goods.

Before characterizing the optimal price, I shall first describe the expect number of matches for suppliers in day-market. Denote by $Q^{i}=Q^{i}\left(x_{i}, k\right)$ the expected number of goods that a supplier $i$ sells per period, given it holds $k$ units and attracts $x_{i}$ buyers on average. It can be computed by

\footnotetext{
${ }^{12}$ Given other buyers are taking the same strategy, $x_{(i)}=\infty$ does not satisfy any given buyer's optimality given $k<\infty$, since it leads to the zero service probability and hence to the zero expected utility.
} 
applying $Q^{i}=x_{i} \eta^{i}$. To see how it works, let $X_{T}$ be a random variable representing the total number of buyers appearing at the supplier $i$. The supplier's expect number of sales out of $k$ units can be decomposed into two parts, depending on the possibility of stockouts.

$$
\begin{aligned}
Q^{i}= & X_{T} \times \text { Prob. }\left(X_{T} \leq k\right)+k \times \text { Prob. }\left(X_{T}>k\right) \\
= & \left\{0 \times \text { Prob. }\left(X_{T}=0\right)+1 \times \text { Prob. }\left(X_{T}=1\right)+\ldots \ldots+k \times \text { Prob. }\left(X_{T}=k\right)\right\} \\
& \quad+\left\{k \times \text { Prob. }\left(X_{T}=k+1\right)+k \times \text { Prob. }\left(X_{T}=k+2\right)+\ldots \ldots\right\} .
\end{aligned}
$$

The terms in the first bracket represent no stockout cases in which smaller than or equal to $k$ buyers show up at $i$, and the supplier $i$ sells $n_{i}=\{0,1, \ldots, k\}$ units. The terms in the second bracket represent stockout cases in which more buyers than the capacity show up, and the supplier sells $k<n_{i}=\{k+1, k+2,, \ldots\}$ units. Applying the Poisson arrival rate yields: ${ }^{13}$

$$
\begin{aligned}
Q^{i} & =\left\{0 \times e^{-x_{i}}+1 \times x_{i} e^{-x_{i}}+\ldots \ldots+k \times \frac{x_{i}^{k} e^{-x_{i}}}{k !}\right\}+k \times\left\{\frac{x_{i}^{k+1} e^{-x_{i}}}{(k+1) !}+\frac{x_{i}^{k+2} e^{-x_{i}}}{(k+2) !}+\ldots \ldots\right\} \\
& =x_{i} \frac{\Gamma\left(k, x_{i}\right)}{\Gamma(k)}+k\left(1-\frac{\Gamma\left(k+1, x_{i}\right)}{\Gamma(k+1)}\right)=x_{i} \eta^{i}
\end{aligned}
$$

From the standpoint of the supplier, $1-\Gamma\left(k+1, x_{i}\right) / \Gamma(k+1)$ represents the probability that the total number of buyers at $i$ is strictly greater than its capacity $k$, which shall be referred to the stockout probability. Stockout is less likely to occur if $x_{(i)}$ is smaller (given $k$ ) or if $k$ is larger (given $x_{i}$ ).

Given the expect number of sales described above, consider now a supplier (i)'s problem to select its price $p_{(i)}$. The supplier $(i)$ expects that its price offer would attract $x_{(i)}$ buyers on average that satisfies equation (2). Its expected profit is the product of the expect number of sales times $p_{(i)}$ :

$$
Q^{i} p_{(i)}=x_{(i)} \eta^{i} p_{(i)}=\left\{x_{(i)} \frac{\Gamma\left(k, x_{(i)}\right)}{\Gamma(k)}+k\left(1-\frac{\Gamma\left(k+1, x_{(i)}\right)}{\Gamma(k+1)}\right)\right\} p_{(i)}
$$

where $k=1$ describes seller's expect profit $(i=s)$ and $k=I$ describes middleman's $(i=m)$. The supplier $(i)$ expects to sell out all $k$ units with probability $Q^{k}\left(x_{(i)}, k\right) / k$ when it posts the price $p_{(i)}$. If the supplier is a seller, then the seller $(s)$ expects to sell its good with probability $Q^{s}=1-e^{-x_{(s)}}$, as often appears in the standard urn-ball matching model.

Taking $V^{b}$ as given, each supplier chooses simultaneously a price to maximize its expect profit subject to buyers' search. In equilibrium, the downward sloping expect-demand imposes price competition among suppliers through buyers' directed search. Given its belief about others' price offers and buyers' search, a high price that induces zero expect demand is not optimal for any given supplier.

\footnotetext{
${ }^{13}$ The derivation of the expect number of sales goes as in Lemma 1 . Note in which bracket the 'tie event' $n_{i}=k$ is included does not matter for this derivation and both ways of calculations give the identical answer.
} 
Hence, by eliminating the price using the demand constraint (2), I obtain:

$$
Q^{i} p_{(i)}=Q^{i}-x_{(i)} V^{b}
$$

The problem is now converted to a choice of $x_{(i)}$. A straightforward algebra shows this objective function is strictly concave in $x_{(i)}$, hence the first order condition characterizes the optimal price.

$$
p_{(i)}=\varphi^{i} \equiv-\frac{\partial \eta^{i} / \partial x_{(i)}}{\eta^{i} / x_{(i)}}=\frac{1-\frac{\Gamma\left(k+1, x_{(i)}\right)}{\Gamma(k+1)}}{Q^{i} / k}
$$

Each period, the optimal price is set equal to the elasticity of the matching function, denoted as $\varphi^{i}=\varphi^{i}\left(x_{(i)}, k\right)$.

The elasticity of the matching function plays a crucial role for the rest of the analysis. It is the ratio of the stockout probability to the probability of clearing-out the goods. When the stockout probability is high, this ratio is high and the price can be set high. In equilibrium, it will turn out that buyers accept a smaller fraction of trading surplus when there is a higher risk of stockouts. Naturally, given $k \geq 1$ fixed, more buyers are expected to yield a higher price, as shown below.

Lemma $2 \quad \partial \varphi^{i} / \partial x_{(i)}>0 ; \quad \lim \varphi^{i}=0$ as $x_{(i)} \rightarrow 0 ; \quad \lim \varphi^{i}=1$ as $x_{(i)} \rightarrow \infty$.

\subsection{Existence, uniqueness and characterization of day-market equilibrium}

The optimality conditions described in the previous sections (taking values of $V^{b}$ as given), are now collected to construct a day-market equilibrium.

Definition 3 Suppose that a measure $S$ of sellers own one unit of good and a measure $M$ of middlemen own $1 \leq I<\infty$ units of goods at the start of each period. A day-market equilibrium in this economy defines a set of expected per-period payoffs $\left\{V^{j}\right\}$ for $j=b, s, m$, and market outcomes $\left\{x_{i}, p_{i}\right\}$, for $i=s, m$, such that:

1. The buyers' directed search satisfies equations (1) and (2);

2. The sellers' and middlemen's price-postings are optimal, satisfying the first order conditions (3) for $i=s, m$;

3. Each period, all agents employ the same strategy and the same type of agents take the same strategy and earn the same per-period expected utility or profit, $V^{j}$ for $j=b, s, m$.

4. Agents' expectations are rational, that is, expected demands are consistent with their equilibrium realizations each period. 
I am now in a position to close the price-search loop. The rational expectation requires that buyers' search should be directed towards the best offer, which yields the highest expected utility $V^{b}$ attainable over the equilibrium prices each period. That is, any buyer's expectation that a price $p_{(i)}$ would receive an expect demand $x_{(i)}$ is self-fulfilling at $x_{i}=x_{(i)}\left(p_{i}, k\right)$ in equilibrium, where no supplier $(i)$ has an incentive to deviate from $p_{(i)}=p_{i}$. This implies in equilibrium: ${ }^{14}$

$$
V^{b}=\eta^{s}\left(x_{s}\right)\left(1-p_{s}\right)=\eta^{m}\left(x_{m}, I\right)\left(1-p_{m}\right) .
$$

Theorem 4 (Day-market equilibrium) Conditioned on $0<M$ and $1 \leq I<\infty$, a day-market equilibrium exists and is unique, where $\left\{x_{i}, p_{i}, V^{j}\right\}$ for $i=s, m$ and for $j=b, s, m$ are the solution to the following equilibrium conditions:

1. Buyer Optimality: $0<V^{b}<1,0<x_{s}<\infty, 0<x_{m}<\infty$ satisfy

$$
\begin{aligned}
V^{b} & =\eta^{s}\left(x_{s}\right)\left(1-p_{s}\right) \\
& =\eta^{m}\left(x_{m}, I\right)\left(1-p_{m}\right) \\
M x_{m}+S x_{s} & =1 .
\end{aligned}
$$

2. Seller Optimality: $0<V^{s}<1,0<p_{s}<1$ satisfy

$$
\begin{aligned}
V^{s} & =Q^{s}\left(x_{s}\right) p_{s} \\
p_{s} & =\varphi^{s}\left(x_{s}\right) .
\end{aligned}
$$

3. Middleman Optimality: $0<V^{m}<I, 0<p_{m}<1$ satisfy

$$
\begin{aligned}
V^{m} & =Q^{m}\left(x_{m}, I\right) p_{m} \\
p_{m} & =\varphi^{m}\left(x_{m}, I\right) .
\end{aligned}
$$

The day-market equilibrium is illustrated in Figure 1. After taking relevant equilibrium conditions into account, $x_{m}$ and $x_{s}$ can be reduced to a strictly decreasing function of $V^{b}$ (given $I \geq 1$ ). This means buyers are better off when the day-market is less tight. Hence, the curve $M x_{m}+S x_{s}$ is downward sloping in $V^{b}$. As equation (6) requires $M x_{m}+S x_{s}=1$, in the figure the intersection identifies the equilibrium value of $V^{b}>0$. If entry of middlemen (i.e., an increase in $M$ ) occurs, more goods are supplied into the day-market. As a result, the intensified competition among suppliers lowers prices, and hence buyers enjoy a higher welfare. This effect is illustrated in the figure by a pivot up of the curve $M x_{m}+S x_{s} \cdot{ }^{15}$ Burdett, Shi, and Wright (2002) study this competitive effect.

\footnotetext{
${ }^{14}$ Hereafter, I will adopt the following notations: $\eta^{s}=\eta^{s}\left(x_{s}\right) ; \eta^{m}=\eta^{m}\left(x_{m}, I\right) ; Q^{s}=Q^{s}\left(x_{s}\right) ; Q^{m}=Q^{m}\left(x_{m}, I\right)$; $\varphi^{s}=\varphi^{s}\left(x_{s}\right) ; \varphi^{m}=\varphi^{m}\left(x_{m}, I\right)$.

${ }^{15} \mathrm{An}$ increase in $M$ leads to a decrease in $x_{s}$ and $x_{m}$, hence to an increase in $V^{b}$, because $x_{s}$ and $x_{m}$ are strictly decreasing in $V^{b}$.
} 


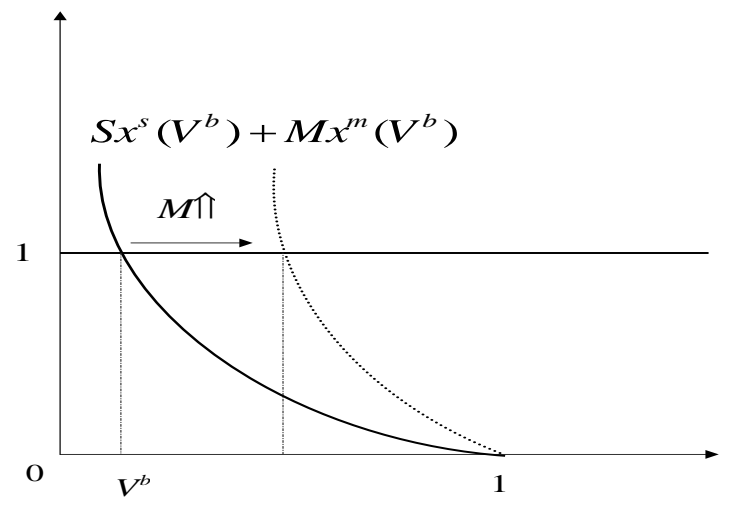

Figure 1: Day-Market Equilibrium

As is common in the competitive search equilibrium, an important property of the day-market equilibrium is that the Hosios's (1990) condition holds endogenously. ${ }^{16}$ That is, the day-market equilibrium prices can be reinterpreted as a solution to the generalized Nash bargaining problem (between each given supplier and buyers) and $p_{i}$ satisfies:

$$
p_{i}=\operatorname{argmax}\left(p_{i}\right)^{\phi^{i}}\left(1-p_{i}\right)^{1-\phi^{i}}
$$

where supplier $i$ 's bargaining power $\phi^{i}$ is equal to the elasticity of the matching function, $\phi^{i}=\varphi^{i}$. This allows for the following interpretation: a high (low) trading risk arising from a high (low) probability of stockouts renders each given supplier a large (small) bargaining power over the terms of trade.

This fact simplifies the buyers' indifference condition. By using equations (8) and (10), the prices in equations (4) and (5) can be substituted out to yield:

$$
V^{b}=\frac{\Gamma\left(I, x_{m}\right)}{\Gamma(I)}=e^{-x_{s}} .
$$

It is clear from this equation that when $I=1$, all suppliers are identical; they attract the identical number of buyers $x_{s}=x_{m}$, offer the identical price $p_{s}=p_{m}$, provide the identical matching service $\eta^{s}=\eta^{m}$, and earn the identical expect profit $V^{s}=V^{m}$.

An increase in the size of each middleman implies an increase in supply (given $M, S>0$ ), hence will increase buyers' welfare and trading volume. However, its effects on the day-market equilibrium are

\footnotetext{
${ }^{16}$ See Moen (1997), Shimer (1996), Shi (2002a,b) and Shimer (2005).
} 
not uniform. On the one hand, an increase in I creates a demand stimulating effect to give middlemen more monopoly power, since buyers become benefited from visiting middlemen more intensively and visiting sellers less intensively when $I$ is larger. ${ }^{17}$ On the other hand, a larger amount of inventory has a bargaining effect of reducing the stockout probability given values of $x_{m}$. That is, when middlemen hold a larger amount of inventory, it is less likely that excess demand occurs at any given middleman. Since buyers know that unsold goods yield zero payoff to middlemen, middlemen can extract only a smaller fraction of trading surplus from buyers per unit of inventory. In other words, a larger inventory creates a higher risk of holding unsold goods, which suppresses the bargaining power of middlemen. ${ }^{18}$ The day-market equilibrium prices are determined to reflect these two effects and in general the combined effects are uneven. However, the following proposition shows that as inventories get sufficiently large, the bargaining effect dominates the demand stimulating effect for the price determination.

Proposition 5 (Competitive limit without intermediated trades) Given a positive measure of middlemen $M>0$, the competitive outcome emerges in the day-market equilibrium described in Theorem 4 in the limit as $I \rightarrow \infty$. That is, the day-market equilibrium satisfies: $p_{s} \rightarrow 0, p_{m} \rightarrow 0$, $x_{m} \rightarrow 1 / M, x_{s} \rightarrow 0, V^{b} \rightarrow 1, V^{m} \rightarrow 0$ and $V^{s} \rightarrow 0$ in the limit as $I \rightarrow \infty$.

The competitive limit in the day-market equilibrium can be understood as follows. First, notice that as middlemen's inventories grow indefinitely, the probability that $n_{m} \leq I$ buyers visit a given middleman $m$ approaches to one, given that the expected number of buyers visiting $m$ is finite. That is, $x_{m} \leq 1 / M$ (by equation (6)) implies:

$$
\frac{\Gamma\left(I, x_{m}\right)}{\Gamma(I)} \rightarrow 1 \quad \text { as } \quad I \rightarrow \infty .
$$

Given any single buyer's visit is negligible for the matching rate when $I \rightarrow \infty$, this means that the service probability of any given buyer from any given middleman approaches to one in the limit as $I \rightarrow \infty$ (i.e., $\eta^{m} \rightarrow 1$ as $I \rightarrow \infty$ ). Second, applying the limiting equation (12) into equation (11) gives:

$$
x_{s} \rightarrow 0 \quad \text { as } \quad I \rightarrow \infty
$$

This further implies by equation (6) that

$$
M x_{m} \rightarrow 1 \quad \text { as } \quad I \rightarrow \infty
$$

\footnotetext{
${ }^{17}$ This is evident by observing that the LHS of equation (11) is strictly increasing in $I$ and is strictly decreasing in $x_{m}$, and that the total amount of buyers' search is fixed by the buyers' population (see equation (6)).

${ }^{18}$ Note that this interpretation is allowed given that the Hosios' condition holds endogenously.
} 
and $\eta^{s} \rightarrow 1$ as $I \rightarrow \infty$. Observe here that the buyer-seller direct trades are completely unraveled in the day-market equilibrium: the visiting probability that each buyer to middlemen approaches to one $\left(M x_{m} \rightarrow 1\right)$, and the visiting probability to sellers approaches to zero $\left(S x_{s} \rightarrow 0\right)$ in the competitive limit. In this situation stockouts (or equivalently excess demand) will never occur at any individual supplier. Because this implies that no tradeoffs between service and price are expected at any given supplier (i.e., $\eta^{s}, \eta^{m} \rightarrow 1$ ), the day-market equilibrium prices converge to the marginal cost $\left(p_{s}, p_{m} \rightarrow 0\right)$ in the limit as $I \rightarrow \infty .^{19}$ Of course, the full service outcome implies the maximum expected trading volume: $M Q^{m}+S Q^{s} \rightarrow 1$ as $I \rightarrow \infty$.

The limiting competitive outcome described above results without any restrictions on population parameters. In the competitive limit, the demand stimulating effect of the middlemen's inventory determines the day-market equilibrium allocations such that the probability that each individual supplier (either a seller or middleman) attracts fewer buyers than the capacity approaches to one. At the same time, the bargaining effect determines the day-market equilibrium prices such that the proportion of trading surplus that any given buyer obtains from each given middleman approaches to one. The result suggests that the relative bargaining power of the agents determines the equilibrium prices even in the limit as frictions disappear. ${ }^{20}$

Before closing this section, it is important to note that the day-market equilibrium is constructed given that each middleman holds $I$ units of inventory every period. At this stage, the intermediation process is not modeled explicitly. If there exist no middlemen, the day-market equilibrium in this economy corresponds to the simplified version of the standard steady-state competitive search equilibrium. Accemoglu and Shimer (1999a,b) study this situation. In such equilibria, an expected measure $S\left(1-Q^{s}\right)$ of sellers do not make a sale each period. The next section will propose how these remaining goods can be supplied to buyers through intermediated trades, i.e., how middlemen can restock their inventory from the sellers each period.

\section{Night market}

The previous section has constructed an equilibrium where a measure $S$ of sellers own one unit of the good and a measure $M$ of middlemen own $I$ units at the beginning of each day. Given the day-market

\footnotetext{
${ }^{19}$ The zero stockout probability (or equivalently, the zero excess demand with probability one) at any individual supplier is the necessary and sufficient condition for the competitive outcome in the day-market equilibrium. If the supplier is a middleman, then the condition is: $1-\frac{\Gamma\left(I+1, x_{m}\right)}{\Gamma(I+1)} \rightarrow 0$ as $I \rightarrow \infty$, that is, the probability that the given middleman receives more buyers than its capacity approaches to zero.

${ }^{20}$ This result is consistent with the Diamond's (1971) result in which even when it becomes costless to change trading partners, the strategic advantage within each pairwise meeting persists for the equilibrium price determination.
} 
equilibrium, this section first shows how the middlemen's initial endowment $I \geq 1$ can be generated endogenously through trades between sellers and middlemen in steady state.

\subsection{Steady-state inventory restocking}

A market is open at night where middlemen can restock their inventory. Suppose now that middlemen have the technology to store the goods for one period as an inventory. ${ }^{21}$ Then, in order to hold $I$ units at the beginning of each day, middlemen need to purchase $I$ units each night. Hence, there is a measure $M I$ of aggregate demand at every night market. Since the remaining goods are valueless for the sellers, there is a measure $S\left(1-Q^{s}\right)$ of aggregate supply available to middlemen at each night-market.

As already mentioned, matching frictions are absent at night. I assume that the steady-state inventory level is determined to balance aggregate demand and aggregate supply at night-market each period. This implies the night-market is cleared out to satisfy the steady-state condition each night: ${ }^{22}$

$$
M I+S Q^{s}\left(x_{s}\right)=S
$$

where $x_{s}$ is determined in Theorem 4 conditioned on values of $I$. Equation (13) is a steady-state requirement to determine the middlemen's initial endowment $I \geq 1$ at the start of each period. I will build a steady-state equilibrium onto the day-market equilibrium to close this inventory-price-search loop. Its fixed-point nature is apparent from the fact that $I$ appears as parameter in Theorem 4 and argument in equation (13).

Definition 6 Suppose that the middlemen's inventory restocking process follows from the steady-state condition (13). Then, a steady-state equilibrium defines the day-market equilibrium described in Theorem 4 with I satisfying equation (13).

Theorem 7 (Steady-state equilibrium) Given $M<S$, a steady-state equilibrium exists with $1 \leq$ $I<\infty .^{23}$

In the steady-state equilibrium, all sellers are cleared out each period: a proportion, $S Q^{s}$, of the goods are sold at today's day-market to buyers, and the remaining proportion, $S\left(1-Q^{s}\right)$, are purchased by middlemen at today's night-market. After selling the good, all sellers produce another

\footnotetext{
${ }^{21}$ The results presented here go through even when middlemen store the goods for more than one period.

${ }^{22}$ Spulber (1996) and Rust and Hall (2003) assume that aggregate demand by buyers and aggregate supply by sellers are assumed to be balanced each period. In my model, the demand-supply balancing condition is stated in terms of middlemen's inventory restocking process.

${ }^{23} M<S$ is required to guarantee $1 \leq I$ in equilibrium.
} 
unit of good for a sale to tomorrow's day-market. This day-night market process is repeated every period in the steady state.

It is worth noting that a positive measure of buyers remain not served each day. The total volume of trades in each day-market, $M Q^{m}+S Q^{s}$, is smaller than both the total demand at day, $M x_{m}+S x_{s}$ (=1), and the total supply at day, $M I+S(\leq 2 S)$. Further, given the steady-state condition (13) holds, the equilibrium allocations in the steady-state satisfy: ${ }^{24}$

$$
M Q^{m}+S Q^{s}<\min \left\{M x_{m}+S x_{s}, M I+S Q^{s}\right\}=\min \{1, S\} .
$$

That is, the middlemen's stationary inventory restocking implies that the flow expect trading volume is bounded either by the total population of buyers $(=1)$ or by the amount of goods produced each period $(=S)$.

\subsection{Scale and quantity of middlemen}

The previous subsection has constructed how the day-market and night-market can be linked to generate intermediary trades. This subsection will show that the configuration of middlemen, in terms of their scale and quantity, determined at night matters to day-market outcomes.

Effects of a change in scale and quantity of middlemen on the day-market outcome can be decomposed into two parts, namely, a day-market effect and a night-market effect. The former works within days while the latter works to feedback from nights to days. If exit of middlemen occurs, day-markets get less competitive if $I$ is fixed and thus the day-market effect works to decrease buyers' welfare and total trading volumes. However, the scale of each middleman will also change at night. The night market-effect is a scale effect, allowing for the operating middlemen restock more inventories at night in response to a decrease in $M$. The larger inventories enable each operating middleman to provide more sure service and to attract more buyers at day. In general, the combined effects of middlemen's exit on the day-market outcome are ambiguous.

When the operating middlemen are sufficiently large-scaled, however, the day-market effect is negligible for the day-market outcome. As mentioned in the previous section, the scale-effect can be decomposed further into the demand stimulating effect and the bargaining effect for the price determination. The following proposition shows the necessary and sufficient conditions for the competitive limit to emerge in this stationary intermediary economy.

\footnotetext{
${ }^{24}$ The first inequality follows from $x_{i}=Q^{i} / \eta^{i}>Q^{i}$, and the second inequality from $I>Q^{m}$.
} 
Proposition 8 (Competitive limit with intermediary trades) Suppose middlemen's inventory restocking process satisfies the steady-state condition (13). Then, the competitive outcome described in Proposition 5 emerges in the steady-state equilibrium in the limit as $M \rightarrow 0$ if and only if $S>1$.

The competitive limit described in Proposition 5 is generalized here by incorporating intermediary trades, given that more goods are produced than the population of buyers $(S>1)$ and that there exist a sufficiently small quantity of middlemen $(M \rightarrow 0)$. The steady-state condition (13) implies that $I \rightarrow \infty$ as $M \rightarrow 0$. In this situation, all buyers anticipate that stockouts will never occur at any given middleman. Their expectations are self-fulfilling in equilibrium only when the operating middlemen restock a sufficiently large number of goods at night. The visiting probability of any given buyer to each seller approaches to zero, and in total more goods are supplied to middlemen at night than the population of buyers $M I \rightarrow S>1$ (given $S>1$ ) in the competitive limit. At the same time, since the stockout probability approaches to zero at any individual suppliers, the day-market prices approach to the marginal cost. As before, the full insurance outcome in the competitive limit implies: $M Q^{m}+S Q^{s} \rightarrow 1<S$ as $I \rightarrow \infty$.

When $S<1$, even though the operating middlemen are large-scaled, the day-market prices satisfy $0<p_{s}<1$ and $0<p_{m}<1$ in the limit as $M \rightarrow 0 .^{25}$ This is because given there exist sellers operating in the day-market, buyers are benefited from assigning some positive visiting probability to each seller when there is an aggregate excess demand. Thus, neither parties possess all the bargaining power within each pairwise meeting, even when the aggregate demand exceeds the aggregate supply in the day-market (i.e., even when $1>2 S \geq S+M I$ ).

This point can be made clear by comparing Proposition 5 and Proposition 8. Without intermediary trades, Proposition 5 shows that excess demand does not occur with probability one at any individual suppliers in the competitive limit. The crucial feature for the competitive result was that the agents in the short-side of any pairwise matches (i.e, buyers) possess all the bargaining power. With intermediary trades, Proposition 8 connects the individual (stochastic) trade imbalances to the aggregate counterpart, and shows that the competitive outcome emerges if there exists excess supply at the aggregate level. In the intermediary economy that I propose, buyers are on the short-side both at the individual and aggregate level in the competitive limit. An interesting question might be to ask if the reverse logic also applies to generate the monopoly price (i.e., $p_{m} \rightarrow 1$ as $M \rightarrow 0$ ) if buyers can be on the long-side both at the individual and aggregate level. If this is the case, the monopoly outcome should require that excess demand occurs with probability one at any individual suppliers.

\footnotetext{
${ }^{25}$ If $S<1$, the stockout probability satisfies: $0<1-\frac{\Gamma\left(I+1, x_{m}\right)}{\Gamma(I+1)}<1$ as $M \rightarrow 0$. In this case, the steady state equilibrium satisfies: $0<x_{s}<\infty, x_{m}=I, 0<p_{s}<1,0<p_{m}<1$ and $I \rightarrow \infty$ in the limit as $M \rightarrow 0$.
} 
To confirm this intuition, the next subsection considers how the aggregate short-side principle can be compatible with the intermediary trades.

\subsection{Walrasian price}

Suppose now that sellers are not operating at day-markets, thus buyers have no option of visiting sellers. Then, the condition describing search frictions, equation (6), is modified to:

$$
M x_{m}=1 .
$$

A measure $S>0$ of goods are produced every period, and supplied to a measure $M>0$ of middlemen every night who hold $I$ units every day. Thus, the steady-state condition (13) is now modified to:

$$
M I=S .
$$

The rest of the setups are exactly the same as before. A symmetric steady-state equilibrium in this simplified economy defines: $0<x_{m}<\infty$ and $0<V^{b}<1$ satisfying (5) and (14); $0<V^{m}<I$ and $0<p_{m}<1$ satisfying (9) and (10); and $1 \leq I<\infty$ satisfying (15). It is straightforward to show the equilibrium exists and is unique given $S>M$.

In this simplified situation, the aggregate supply (the aggregate demand) is vertical line $S$ (one). Hence, buyers (middlemen) are on the short-side of day-markets if $S>1$ (if $S<1$ ). The Walrasian price in this economy, which I denote as $p_{w}$, defines:

$$
p_{w}=\left\{\begin{array}{cc}
0 & \text { if } S>1 \\
(0,1) & \text { if } S=1 \\
1 & \text { if } S<1
\end{array}\right.
$$

For any $0<M<S$, the day-market does not clear each period on both sides of the market (i.e. $0<\eta^{m}<1$ and $\left.0<Q^{m}<1\right)$ in the steady state equilibrium, and hence $p_{m} \neq p_{w}$. However, the following proposition shows that the equilibrium price that middlemen set in this simplified economy can be Walrasian in the limit as the proportion of middlemen becomes sufficiently small. ${ }^{26}$

Proposition 9 (Walrasian price with intermediary trades) Suppose that sellers do not operate in the day-market in the steady-state equilibrium. Then in the limit as $M \rightarrow 0$, the market price in this economy approaches to the Walrasian price: $p_{m} \rightarrow p_{w}$ as $M \rightarrow 0$.

\footnotetext{
${ }^{26}$ The following proposition can be shown by noting that $x_{m} \rightarrow \infty$ and $I \rightarrow \infty$ as $M \rightarrow 0$. The proof takes similar steps as in the proof of Proposition 8, so is in the Additional Appendix. The result holds even when middlemen hold goods for more than one period.
} 
Within this simplified economy, expected trade imbalances at the individual level $x_{m} \geq I$ is determined solely by the aggregate condition $S \leq 1$, as evident from comparing equations (14) and (15). Given that sellers do not operate in the day-market, Proposition 9 claims that middlemen can carry out the short-side principle for the equilibrium price determination in the limit as $M \rightarrow 0$. If there exists an aggregate excess supply $S>1$, the stockout probability approaches to zero at the individual level. Therefore, the proportion of trading surplus that any given buyer receives in each pairwise meeting approaches to one, $p_{m} \rightarrow 0$ in the limit as $M \rightarrow 0$ if $S>1$. This case corresponds to the competitive limit shown in Proposition 8, in which the service probability for any given buyer approaches to one (i.e., $\eta^{m} \rightarrow 1$ as $M \rightarrow 0$ if $S>1$ ). Conversely, if there exists an aggregate excess demand $S<1$, the stockout probability approaches to one at the individual level. ${ }^{27}$ Therefore, the proportion of trading surplus that any given buyer receives in each pairwise meeting approaches to zero, $p_{m} \rightarrow 1$, in the limit as $M \rightarrow 0$ if $S<1$. In this case, the probability of clearing out the goods approaches to one at any given middleman (i.e., $Q^{m} / I \rightarrow 1$ as $M \rightarrow 0$ if $S<1$ ).

These results suggest that when market frictions disappear in either side of the market, the shortside of the agents at the individual level coincides with the aggregate counterpart and the short-side of the agents have all the bargaining power. ${ }^{28}$

Summarizing, I have shown that middlemen can emerge endogenously to mitigate matching frictions. In the limit as the proportion of middlemen gets sufficiently small, the competitive outcome emerges in which buyers are all served with probability one and they all choose to trade with middlemen. This result suggests that the centralization of resource allocations through middlemen can resolve trade imbalances, which could be termed as a vertical centralization phenomenon. Further, middlemen can carry out the short-side principle for the market price to be Walrasian. It might be interesting to imagine here that the market-clearing process manifests itself through merchant traders who act as central trade-coordinators to resolve market frictions.

\footnotetext{
${ }^{27}$ That is, within this simplified economy, the following is true: $1-\frac{\Gamma\left(I+1, x_{m}\right)}{\Gamma(I+1)} \rightarrow 0$ as $M \rightarrow 0$ if $S>1 ; 1-\frac{\Gamma\left(I+1, x_{m}\right)}{\Gamma(I+1)} \rightarrow$ 1 as $M \rightarrow 0$ if $S<1$.

${ }^{28}$ It is interesting to observe that this result is somehow related to De Fraja and Sakovics (2001) which develops a bargaining model to allow for local market conditions vary independently of global conditions. Although the notion of frictions in their model is quite different from mine, De Fraja and Sakovics show without intermediary trades that there exist generic matching technologies, which can yield the Walrasian outcome, only when the locally and globally short-sides coincide.
} 


\section{Discussion}

Related literature - functions of middlemen The present framework contributes to the literature of intermediation by integrating the key functions of middlemen into a unified framework, each of which has been separately studied elsewhere - market makings, price competition and inventory holdings. This new approach provides novel insights into the role of middlemen and the issue of the price formation that are missing in the literature.

The closely related areas to my paper can be classified into two. ${ }^{29}$ The first strand studies the middleman's role of market making with frictions. Using a bilateral random matching model, Rubinstein and Wolinsky (1987) show that middlemen are active in equilibrium by assuming that middlemen have a higher meeting rate than sellers and buyers. The middlemen's advantage in the matching technology centers the subsequent extension, but to be derived endogenously. Li (1998) considers an environment where the qualities of goods are private information, and claims that middlemen invest in identifying the quality of goods. Shevichenko (2004) provides an intriguing insight into the role of middlemen, by developing a model where middlemen collect various types of goods to satisfy various types of agents' tastes. Shevichenko's model and mine share a similar mechanism in which middlemen's inventory holdings are endogenously linked to their matching effectiveness. The demand stimulating effect of inventory holdings, however, arises without resource to ex-ante heterogeneity in my model. Another feature in this strand is that the terms of trades are determined by bilateral bargaining, hence price competition among middlemen is absent in these models.

The middlemen's role of price setting is considered with their price competition in Spulber (1996), but still within a random meeting framework. Because middlemen are assumed to be the only medium of exchange in his model, the subsequent extensions were made to incorporate an additional avenue of exchange to study the conditions under which middlemen survive in equilibrium - a monopolist market maker in Rust and Hall (2003) and buyer-seller direct trades in Hendershott and Zhang (2003). However, the two important issues are not considered in this strand. First, since the matching technology in this approach is exogenous, middlemen's advantage in the high meeting rate cannot be the issue. Second, since the demand-supply balance is imposed as a constraint each period, there is no room for inventories to play any economic role (see Rust and Hall, pp.400-01). In my framework, the competitive search equilibrium enables price competition to play the role for intermediation, and the

\footnotetext{
${ }^{29}$ There are many other important issues that I have not addressed in this paper. A non-exhaustive list includes Biglaiser (1993), Caillaud and Jullien (2003), Gehrig (1993), Johri and Leach (2002), Masters (2005), Rochet and Tirole (2004), and Smith (2002).
} 
underlying directed matching structure that I propose can provide a natural endogenous link between inventory holdings and a high matching rate that middlemen provide to buyers. ${ }^{30}$

Empirical Implications The analysis presented suggests that the presence of a small number of large-scaled middlemen introduces a competitive pressure on the retail market where middlemen have been absent initially. An empirical implication of this result is that an entry of a big supermarket, who attracts a large number of consumers, into a local town where only small retailers have been operating will decrease the overall retail market price. Basker (2005) found in a case study that an entry of Wal-Mart stimulates competition at the local level in 165 US cities.

My model also suggests that retail stockouts are an important variable for explaining retail market prices. First of all, evidence suggests that stockouts are prevalent in retail markets. Andersen Consulting (1996) reports that $8.2 \%$ of the items were out of stock on a typical day in a typical supermarket. An important analysis from the economics perspective is pursued by Aguirregabiria (2005) who finds that intermediaries' inventory accumulation is crucial to explain their pricing patterns, when customers trade-off the price against the service rate.

There are evidence that shows the significant effects of inventory holdings on supermarket prices. Aguirregabiria (1999) shows a negative effect of inventory ordering on the markups is consistent with data in a supermarket chain. In my framework, the negative effect of inventory accumulation on the retail prices is explained by the presence of the risk for middlemen to hold unsold inventories (i.e., bargaining effects). In connection with this, retailers' price increases following supermarket leveraged buyouts (LBOs) are observed in Chevalier (1995). This evidence can be consistent with the prediction of the present model, given that high leverage may lead firms to be cash-constrained and hence may force them to reduce their size. This will be an testable implication.

\section{Conclusion}

This paper has presented a framework that integrates three key functions of intermediaries, each of which has been separately studied in the literature: (1) market-makings to link producers and consumers; (2) price competition to set price; (3) providing liquidity or immediacy to hold an inventory.

\footnotetext{
${ }^{30}$ It might be interesting to note that the present study is consistent with a recent development in monetary economics. The role of money is similar to the role of middlemen in that both mitigate matching frictions to facilitate trades. Corbae, Temzelides and Wright (2003) show that the essential role of money is robust to a directed-matching environment. My analysis provides a similar insight into a medium of exchange: middlemen survive even when agents are ex ante homogeneous and have ability to choose with whom to match.
} 
The paper shows how middlemen can emerge endogenously to accomplish these triple tasks and mitigate market frictions. This new approach provides novel insights into the process of price formation and a rich understanding of middlemen. The centralized resource allocations through middlemen, which arises endogenously, can resolve coordination frictions and yield the competitive outcome. The paper has also characterized the conditions under which the middlemen that I propose can carry out the short-side principle for the market prices to be Walrasian.

The idea proposed in this paper that middlemen can emerge to coordinate transactions by holding an inventory is quite simple and appealing. Indeed, the issue of market making was considered by Clower and Leijonhufvud (1979) who observed that in the presence of frictions and in the absence of the Walrasian auctioneer, "natural forces of greed and competition might plausibly be invoked to provide a rationale for the gradual emergence of merchant traders and organized markets" (p.184). They suggest an inventory-based competitive 'supermarket' story, although in my paper why and how middlemen emerge are endogenously derived. The model is applicable to analyze various types of market exchanges. An interesting extension would be to incorporate ex-ante heterogeneity in buyers' preferences or traveling costs with imperfect information. This would allow the model to describe situations where a large number of small-sized middlemen fit well. Also, the model can be easily inserted into the standard neoclassical growth framework to endogenize the production process. In this vein, Faig and Jerez (2005) propose an interesting directed-search model with imperfect information, but without intermediation and inventory holdings. Any rate, generalization of the idea developed here to analyze other related aspects of market exchanges remains for future work. 


\section{Appendix}

Throughout the proofs in this appendix, I simplify the notation to set $x=x_{(i)}=x_{i}$ and $\eta=\eta^{(i)}=\eta^{i}$ when it will not cause confusion.

\subsection{Proof of Lemma 1}

Suppose continuum of buyers are measured by an interval $(0,1]$ and let $X \equiv X((0,1])$ be a random variable counting the number of event that a buyer appears to a particular supplier or not. For $\forall i=1,2, \ldots$ and for any distinct points $b_{0}=0<b_{1}<b_{2}<\ldots<b_{i}$, define $X((a, b])$ to be the number of buyers $b_{i}$ who visit a particular supplier, from the buyers located at an interval $(a, b]$, where $a<b_{i} \leq b$. Since $X\left(\left(b_{i-1}, b_{i}\right]\right)$ are independent random variables, the event that a single buyer shows up or not constitutes a Bernoulli trial for any single suppliers, as commonly employed to describe a large market in the directed matching literature.

Given the above postulations, the event that a certain number of buyers arrive at any particular supplier follows a Poisson counting process. When a buyer visits a particular supplier who has $k \in \mathcal{Z}_{+}$ units of inventory, she/he would get a good with the following probability:

$$
\begin{aligned}
\eta & =\operatorname{Pr}(X \leq k-1) \operatorname{Pr}(\text { served } \mid X \leq k-1)+\operatorname{Pr}(X \geq k) \operatorname{Pr}(\text { served } \mid X \geq k) \\
& =\sum_{j=0}^{k-1} \frac{x^{j} e^{-x}}{j !}+\sum_{j=k}^{\infty} \frac{x^{j} e^{-x}}{j !} \frac{k}{j+1},
\end{aligned}
$$

where $x$ defines the expected number of buyers per supplier. If $X$ counts less than the given supplier's capacity, the buyer would get served with probability one by visiting the supplier (the first term above). Otherwise, there might be a possibility of rationing and she/he gets served with probability $\frac{k}{j+1}$, where $j \in\{k, k+1, \ldots, \infty\}$ counts the realized number of buyers who appear at the given supplier (the second term above). A rearrangement yields:

$$
\begin{aligned}
\eta & =\sum_{j=0}^{k-1} \frac{x^{j} e^{-x}}{j !}+k \sum_{j=0}^{\infty} \frac{x^{j} e^{-x}}{(j+1) !}-k \sum_{j=0}^{k-1} \frac{x^{j} e^{-x}}{(j+1) !} \\
& =\frac{\Gamma(k, x)}{\Gamma(k)}+\frac{k}{x}\left(1-e^{-x}\right)-\frac{k}{x}\left(\frac{\Gamma(k+1, x)}{\Gamma(k+1)}-e^{-x}\right) \\
& =\frac{\Gamma(k, x)}{\Gamma(k)}+\frac{k}{x}\left(1-\frac{\Gamma(k+1, x)}{\Gamma(k+1)}\right) .
\end{aligned}
$$

To reach the second equality above, the following manipulations will be performed. The first term can be obtained by applying $\sum_{j=0}^{k-1} \frac{x^{j} e^{-x}}{j !}=\frac{\Gamma(k, x)}{\Gamma(k)}$ (the series definition of the cumulative gamma function), which can be derived by repeating integration by parts $k-1$ times as follows:

$$
\begin{aligned}
e^{-x} \sum_{j=0}^{k-1} \frac{x^{j}}{j !} & =\frac{1}{(k-1) !}\left\{\frac{(k-1) !}{0 !} e^{-x}+\frac{(k-1) !}{1 !} x e^{-x}+\ldots+\frac{(k-1) !}{(k-1) !} x^{k-1} e^{-x}\right\} \\
& =\frac{1}{(k-1) !}\left\{(k-1) ! \int_{x}^{\infty} t e^{-t} d t+\frac{(k-1) !}{2 !} x^{2} e^{-x}+\ldots+\frac{(k-1) !}{(k-1) !} x^{k-1} e^{-x}\right\} \\
& =\frac{1}{(k-1) !}\left\{\frac{(k-1) !}{(k-2) !} \int_{x}^{\infty} t^{k-2} e^{-t} d t+\frac{(k-1) !}{(k-1) !} x^{k-1} e^{-x}\right\} \\
& =\frac{1}{(k-1) !} \int_{x}^{\infty} t^{k-1} e^{-t} d t \quad\left(=\frac{\Gamma(k, x)}{\Gamma(k)}\right),
\end{aligned}
$$

where $\Gamma(k)=\int_{0}^{\infty} t^{k-1} e^{-t} d t$ is the gamma function and $\Gamma(k, x)=\int_{x}^{\infty} t^{k-1} e^{-t} d t$ is the incomplete gamma function. To obtain the closed form expression in the second term, I set $h=j+1$ and go as 
follows:

$$
\sum_{j=0}^{\infty} \frac{x^{j} e^{-x}}{(j+1) !}=\sum_{h=1}^{\infty} \frac{x^{h-1} e^{-x}}{h !}=\frac{1}{x} \sum_{h=1}^{\infty} \frac{x^{h} e^{-x}}{h !}=\frac{1}{x}\left(\sum_{h=0}^{\infty} \frac{x^{h} e^{-x}}{h !}-e^{-x}\right)=\frac{1}{x}\left(1-e^{-x}\right) .
$$

Finally, the third term can be obtained by combining the two manipulations described above. Further, it is immediately shown that $\eta$ is strictly decreasing in $x$ and strictly increasing in $k$, and satisfies: $\eta(0, k)=1, \lim \eta(x, k)=0$ as $x \rightarrow \infty, \lim \eta(x, k)=1$ as $k \rightarrow \infty$. QED

\subsection{Proof of Lemma 2}

In this proof, I first show that:

$$
\frac{\partial \varphi}{\partial x}=-\frac{\partial \eta / \partial x}{\eta(x)^{2}}\left\{\eta(x)\left(1+x \frac{\partial^{2} \eta(x) / \partial x^{2}}{\partial \eta(x) / \partial x}\right)-x \frac{\partial \eta(x)}{\partial x}\right\}>0
$$

For this, it is sufficient to show that the first term in the bracket is positive given $\frac{\partial \eta(x)}{\partial x}<0$. By noting that $\Gamma(k+1)=k \Gamma(k)$ and $\Gamma(k, x)=-\frac{1}{k}\left\{x e^{-x}-\Gamma(k+1, x)\right\}$, the term $\frac{\partial^{2} \eta(x)}{\partial x^{2}}$ can be written as follows:

$$
\frac{\partial^{2} \eta(x)}{\partial x^{2}}=\frac{k}{x^{3}}\left\{1-\frac{\Gamma(k+1, x)}{\Gamma(k+1)}-x\left(\frac{\Gamma(k+1, x)}{\Gamma(k+1)}-\frac{\Gamma(k, x)}{\Gamma(k)}\right)\right\} .
$$

Using this equation, it follows that:

$$
1+x \frac{\partial^{2} \eta(x) / \partial x^{2}}{\partial \eta(x) / \partial x}=\frac{x\left\{\frac{\Gamma(k+1, x)}{\Gamma(k+1)}-\frac{\Gamma(k, x)}{\Gamma(k)}\right\}}{1-\frac{\Gamma(k+1, x)}{\Gamma(k+1)}}>0 .
$$

This proves the first property presented in Lemma 2. The second and third properties are immediate by applying the l'Hospital's rule once. QED

\subsection{Proof of Theorem 4}

The previous analysis has established that equations (4)-(10) describe necessary and sufficient conditions for an equilibrium. All that remains here is to establish a solution to those conditions, $\left\{x_{i}, p_{i}, V^{j}\right\}$, for $i=s, m$ and $j=b, s, m$, exists and is unique. The proof takes 4 steps. Step 1 establishes that equilibrium requires $0 \leq V^{b} \leq 1,0 \leq V^{s} \leq 1$. For any $0 \leq V^{b} \leq 1$, Step 2 establishes that equations $(4),(7),(8)$ imply a unique solution for $x_{s} \geq 0$. With a slight abuse of notation, let $x_{s}\left(V^{b}\right)$ denote that solution. Similarly for any $0 \leq V^{b} \leq 1$, Step 3 establishes that equations (5),(10) imply a unique solution for $x_{m} \geq 0$. Let $x_{m}\left(V^{b}\right)$ denote that solution. An equilibrium is then identified by noting equation (6) requires $V^{b}$ satisfies the fixed point condition:

$$
M x_{m}\left(V^{b}\right)+S x_{s}\left(V^{b}\right)=1,
$$

where $M, S$ are positive constants. Using Steps 2 and 3, Step 4 establishes that a $0<V^{b}<1$ satisfying this condition exists and is unique. Hence Step 4 establishes an equilibrium exists and is unique: given $V^{b}$ satisfying equation (16), $0<x_{s}<\infty$ and $0<x_{m}<\infty$ are uniquely determined in Step 2 and 3 respectively, $0<V^{s}<1$ is uniquely determined in Step 1, and $0<V^{m}<I$ is uniquely determined by (9). Finally, $0<x_{s}<\infty$ and $0<x_{m}<\infty$ in turn determine a unique solution $0<p_{s}<1$ and $0<p_{m}<1$ respectively by (8) and (10). By construction, this solution then satisfies equations (4)-(10) and so describes equilibrium. 
Step 1 Equilibrium implies $0 \leq V^{b} \leq 1$ and $0 \leq V^{s} \leq 1$

Proof of Step 1. Equations (4),(7),(8) imply $V^{b}, V^{s}$ satisfies:

$$
V^{b}=e^{-x_{s}} \quad \text { and } \quad V^{s}=1-e^{-x_{s}}-x_{s} e^{-x_{s}} .
$$

Note that the RHS of the first equation is decreasing in $x_{s}$ and the RHS of the second equation is increasing in $x_{s}$. As equilibrium implies $x_{s} \geq 0$, it follows that $0 \leq V^{b} \leq 1$ and $0 \leq V^{s} \leq 1$. This completes the proof of Step 1.

Step 2 For any $0 \leq V^{b} \leq 1$, a solution for $x_{s} \geq 0$ defined by equations $(4),(7),(8)$ exists, is unique and implies: $x_{s}\left(V^{b}\right)$ is continuous and strictly decreasing in $V^{b}$ and satisfies $\lim x_{s}\left(V^{b}\right)=\infty$ as $V^{b} \rightarrow 0$ and $x_{s}(1)=0$.

Proof of Step 2. The result is immediate by the inverse function theorem and by noting that for any $x_{s} \geq 0, V^{b}$ is continuous, strictly decreasing in $x_{s}$ (by Step 1), and hence invertible. This completes the proof of Step 2.

Step 3 For any $0 \leq V^{b} \leq 1$, a solution for $x_{m} \geq 0$ defined by equations (5),(10) exists, is unique and implies: $x_{m}\left(V^{b}\right)$ is continuous and strictly decreasing in $V^{b}$ and satisfies $\lim x_{m}\left(V^{b}\right)=\infty$ as $V^{b} \rightarrow 0$ and $x_{m}(1)=0$.

Proof of Step 3. By substituting $p_{m}$ in (10) into (5) and by using Step 2,

$$
\frac{\Gamma\left(I, x_{m}\right)}{\Gamma(I)}=e^{-x_{s}\left(V^{b}\right)} .
$$

By Step 2, the RHS of this equation is continuous, strictly increasing in $V^{b}$ and takes 0 when $V^{b}=0$ and takes 1 when $V^{b}=1$. The LHS is continuous and strictly decreasing in $x_{m}$, and takes 1 when $x_{m}=0$ and approaches to 0 as $x_{m} \rightarrow \infty$. Therefore, there exists a unique solution $x_{m}\left(V^{b}\right)$ which is continuous and strictly decreasing in $V^{b}$, and satisfies $\lim x_{m}\left(V^{b}\right)=\infty$ as $V^{b} \rightarrow 0$ and $x_{m}(1)=0$. This completes the proof of Step 3.

Step 4 There exists a unique $0<V^{b}<1$ which satisfies (16).

Proof of Step 4. By Step 2 and Step 3, the LHS of (16) is continuous, strictly decreasing in $V^{b}$ and approaches to $\infty$ as $V^{b} \rightarrow 0$ and takes 0 when $V^{b}=1$. Because the RHS of (16) is a positive constant, we must have a unique $0<V^{b}<1$. This completes the proof of Step 4. QED

\subsection{Proof of Proposition 5}

Note first that in the day-market equilibrium, $x_{m} \leq 1 / M$ holds given $M>0$. The claim can be shown by using the following property (see the proof of proposition 8 for this property): when $x_{m}<I$,

$$
\frac{\Gamma\left(I, x_{m}\right)}{\Gamma(I)} \rightarrow 1 \quad \text { as } \quad I \rightarrow \infty .
$$

This implies: $x_{s} \rightarrow 0$ as $I \rightarrow \infty$ by equation (11). Applying the limit $x_{s} \rightarrow 0$ as $I \rightarrow \infty$ into equations (4), (7), (8) yields: $\eta^{s} \rightarrow 1, V^{b} \rightarrow 1, p_{s} \rightarrow 0, V^{s} \rightarrow 0$ as $I \rightarrow \infty$. Further, equation (6) implies: $x_{m} \rightarrow 1 / M$ as $I \rightarrow \infty$. Given $V^{b} \rightarrow 1$ as $I \rightarrow \infty$, equation (5) implies that: $\eta^{m} \rightarrow 1$ and $p_{m} \rightarrow 0$ as $I \rightarrow \infty$. By noting that $Q^{m} \rightarrow x_{m}<\infty$ as $I \rightarrow \infty$, this further implies: $V^{m}=Q^{m} p_{m} \rightarrow 0$ as $I \rightarrow \infty$ by equation (9). QED 


\subsection{Proof of Theorem 7}

The proof is similar to that of Theorem 4 and proceeds according to the following steps. As mentioned in the main text, equations $(4),(5),(8),(10)$ can be reduced to equation (11). Using equations (6),(11), Step 1 solves for a unique $x_{s} \geq 0$ for any $1 \leq I<\infty$. With a slight abuse of notation, let $x_{s}(I)$ denote this solution. Step 2 then identifies an equilibrium by noting equation (13) requires $I$ satisfies the fixed point condition:

$$
M I+S Q^{s}\left(x_{s}(I)\right)=S,
$$

where $0<M<S$ is a positive constant. Hence using Step 1, Step 2 establishes that an $1 \leq I<\infty$ exists that satisfies this condition. This implies an equilibrium exists: given $I$ satisfying (17), Step 1 pins down $0<x_{s}<\infty$; given this solution, equation (6) pins down $0<x_{m}<\infty$; other equilibrium values are identified by the same procedure as in Theorem 4 using equations (4),(7),(8),(9). By construction, this solution then satisfies equations (4)-(10),(13) and so describes equilibrium.

Step 1 For any $1 \leq I<\infty$, a solution for $x_{s}$ defined by equations (6),(11) exists and is unique. $\overline{\text { Further}}$, there exists a continuous function $x_{s}(I)$ that satisfies: $x_{s}(1)=1 /(S+M) ; \lim x_{s}(I)=0$ as $I \rightarrow \infty$.

Proof of Step 1. Substituting out $x_{m}$ in equation (11) by using equation (6) yields:

$$
\frac{\Gamma\left(I, \frac{1-S x_{s}}{M}\right)}{\Gamma(I)}=e^{-x_{s}} .
$$

The LHS of this equation is strictly increasing in $x_{s}$, takes $\frac{\Gamma(I, 1 / M)}{\Gamma(I)}<1$ when $x_{s}=0$ and takes 1 when $x_{s}=1 / S$. Similarly, the RHS is strictly decreasing in $x_{s}$ and takes 1 when $x_{s}=0$ and $e^{-1 / S}<1$ when $x_{s}=1 / S$. Hence, there exists a unique solution $0<x_{s} \leq 1 / S$ to this equation for any $1 \leq I<\infty$.

Further, the LHS of the above equation is continuous function of $I$, which takes $e^{-\left(1-S x_{s}\right) / M}$ when $I=1$ and approaches to 1 when $I \rightarrow \infty$. This implies there exists a continuous function $x_{s}=x_{s}(I)$ that satisfies: $x_{s}(1)=1 /(S+M) ; \lim x_{s}(I)=0$ as $I \rightarrow \infty$. This completes the proof of Step 1 .

Step 2 There exists an $1 \leq I<\infty$ which satisfies (17).

Proof of Step 2. By Step 1, the LHS of (17) is continuous function of $I$, which takes $M+S(1-$ $e^{-1 /(S+M)}$ ) when $I=1$ and approaches to $\infty$ as $I \rightarrow \infty$. Hence, given $M<S$, this guarantees the existence of a solution, $1 \leq I<\infty$, to (17). This completes the proof of Step 2. QED

\subsection{Proof of Proposition 8}

Before proceeding, note equation (13) implies that the following must be satisfied given $S>0$ :

$$
I \rightarrow \infty \text { and } 0<M I<\infty \text { as } M \rightarrow 0 .
$$

Keeping this in mind, the proof proceeds as follows. As shown in the proof of Theorem 7, the steady-state equilibrium value of $x_{s}, x_{m}, I$ are fully characterized by equations (6),(11),(13). Hence, assuming $S>1$, Step 1 shows that equations (6),(11),(13) imply: $x_{s} \rightarrow 0$ as $M \rightarrow 0$. Using this result, Step 2 shows: $x_{m}<I$ and $M x_{m} \rightarrow 1$ as $M \rightarrow 0$. Applying these results to other equilibrium requirements (4),(5),(7),(8),(9),(10), Step 3 establishes that the steady-state equilibrium approaches to the competitive outcome in the limit as $M \rightarrow 0$. 
The proof given below is largely based on the following property which has been established in the special function literature (see Temme (1996) p.285):

$$
\frac{\Gamma(I, x)}{\Gamma(I)} \rightarrow D \text { as } I \rightarrow \infty
$$

where $0 \leq D \leq 1$, and $D=1$ iff $x<I$ and $D=0$ iff $x>I$. I shall refer to it as [Property T]. Additional Appendix provides the proof of this property for interested (or suspicious) readers.

Step 1 Equations (6),(11),(13) imply that: $x_{s} \rightarrow 0$ as $M \rightarrow 0$ given $S>1$.

Proof of Step 1. The claim can be proved by contradiction. Suppose $x_{s}>0$ as $M \rightarrow 0$. Then, given $I \rightarrow \infty$ as $M \rightarrow 0$, equation (11) implies that:

$$
0<\frac{\Gamma\left(I, x_{m}\right)}{\Gamma(I)}=e^{-x_{s}}<1 \quad \text { as } \quad M \rightarrow 0 .
$$

This further implies: $x_{m}=I$ as $M \rightarrow 0$ by [Property T]. By substituting $M x_{m}=M I$ into equations (6),(13), it turns out that the limiting value of $x_{s}>0$ as $M \rightarrow 0$ must satisfy: $S\left(e^{-x_{s}}+x_{s}\right)=1$. However, there does not exist a solution $x_{s}>0$ to this equation given $S>1$, hence a contradiction. This completes the proof of Step 1.

Step 2 Given that $x_{s} \rightarrow 0$ as $M \rightarrow 0$, equations (6), (11), (13) imply $x_{m}<I$ and $M x_{m} \rightarrow 1$ as $\overline{M \rightarrow 0}$.

Proof of Step 2. When $x_{s} \rightarrow 0$ as $M \rightarrow 0$, equation (11) implies (given $I \rightarrow \infty$ as $M \rightarrow 0$ ):

$$
\frac{\Gamma\left(I, x_{m}\right)}{\Gamma(I)}=e^{-x_{s}} \rightarrow 1 \quad \text { as } \quad M \rightarrow 0 .
$$

This further implies: $x_{m}<I$ as $M \rightarrow 0$ by [Property T]. $M x_{m} \rightarrow 1$ as $M \rightarrow 0$ can be shown by applying the limiting value $x_{s} \rightarrow 0$ as $M \rightarrow 0$ to equation (6). This completes the proof of Step 2 .

Step 3 Given the results obtained in Step 1 and Step 2, the steady-state equilibrium approaches to the competitive limit as $M \rightarrow 0$.

Proof of Step 3. Applying $x_{s} \rightarrow 0$ as $M \rightarrow 0$ to equations (4), (7), (8) gives: $V^{b} \rightarrow 1, \eta^{s} \rightarrow 1$, $V^{s} \rightarrow 0, p_{s} \rightarrow 0$ as $M \rightarrow 0$. Also, $V^{b} \rightarrow 1$ as $M \rightarrow 0$ implies $\eta^{m} \rightarrow 1$ and $p_{m} \rightarrow 0$ as $M \rightarrow 0$ by equation (5). Further, note that [Property T] implies:

$$
I\left(1-\frac{\Gamma\left(I+1, x_{m}\right)}{\Gamma(I+1)}\right) \rightarrow 0 \quad \text { as } \quad I \rightarrow \infty,
$$

when $x_{m}<I$. Using this property, the limit value of $V^{m}$ can be identified by equation (9):

$$
V^{m}=Q^{m} p_{m}=I\left(1-\frac{\Gamma\left(I+1, x_{m}\right)}{\Gamma(I+1)}\right) \rightarrow 0 \quad \text { as } \quad M \rightarrow 0,
$$

(given $x_{m}<I$ and $I \rightarrow \infty$ as $M \rightarrow 0$ ). This completes the proof of Step 3. QED 


\section{Additional Appendix (only to referees)}

\subsection{Complementary Proof of Lemma 1}

The objective of this complementary proof is to show that the matching probability described in Lemma 1 under continuum agents can be derived as the limiting probability under its finite-agents setup counterpart. Suppose now $N_{b}, N_{s}, N_{m}$ represent the number of buyers, sellers, and middlemen respectively that are positive integers. Suppose also that any buyers assign a probability $\alpha_{m}, \alpha_{s}$ to each individual middleman and seller respectively, satisfying $N_{m} \alpha_{m}+N_{s} \alpha_{s}=1$. As I only characterize here the matching probability to middlemen, I simplify the notation to set $\alpha=\alpha_{m}$. Hereafter, by saying 'limit' (or 'lim') I will mean the limit as all $N_{b}, N_{s}, N_{m}$ go to infinity with keeping the ratios $N_{b} / N_{m}, N_{s} / N_{m}$ constant. Define $x \equiv \lim N_{b} \alpha_{m}$ to be the expect number of buyers at a given middleman in the limit.

In this finite setup, when a buyer visits a given middleman who has $I$ units of goods, she/he would get one of the goods with the following probability:

$$
\eta^{m}=\sum_{j=0}^{I-1} C_{N_{b}-1}^{j} \alpha^{j}(1-\alpha)^{N_{b}-1-j}+\sum_{j=I}^{N_{b}-1} \frac{I}{j+1} C_{N_{b}-1}^{j} \alpha^{j}(1-\alpha)^{N_{b}-1-j},
$$

where $C_{N_{b}-1}^{j}=\frac{\left(N_{b}-1\right) !}{j !\left(N_{b}-1-j\right) !}$. If the number of other buyers visiting the middleman is less than $I$, the buyer gets served by visiting the middleman with probability one (the first term), otherwise with probability $\frac{I}{j+1}, j \in\left\{I, I+1, \ldots, N_{b}-1\right\}$ (the second term). A rearrangement with applying the binomial theorem yields:

$$
\begin{aligned}
\eta^{m} & =\sum_{j=0}^{N_{b}-1} \frac{I}{j+1} C_{N_{b}-1}^{j} \alpha^{j}(1-\alpha)^{N_{b}-1-j}+\sum_{j=0}^{I-1}\left(1-\frac{I}{j+1}\right) C_{N_{b}-1}^{j} \alpha^{j}(1-\alpha)^{N_{b}-1-j} \\
& =\frac{I}{N_{b} \alpha}\left\{1-(1-\alpha)^{N_{b}}\right\}+\sum_{j=0}^{I-1}\left(1-\frac{I}{j+1}\right) C_{N_{b}-1}^{j} \alpha^{j}(1-\alpha)^{N_{b}-1-j} \\
& \equiv \eta_{1}^{m}+\eta_{2}^{m} .
\end{aligned}
$$

It is obvious that the first term $\eta_{1}^{m}$ in this expression satisfies:

$$
\lim \eta_{1}^{m}=\lim \frac{I}{N_{b} \alpha}\left\{1-(1-\alpha)^{N_{b}}\right\}=\frac{I}{x}\left(1-e^{-x}\right) .
$$

The limit of the second term $\eta_{2}^{m}$ is calculated as follows. First, opening $I$ number of terms of this series gives:

$$
\begin{aligned}
\eta_{2}^{m}=(1-I)(1-\alpha)^{N_{b}-1}+\left(1-\frac{I}{2}\right)\left(N_{b}-1\right) \alpha(1-\alpha)^{N_{b}-2}+\ldots \\
\\
\ldots+\left(1-\frac{I}{h}\right) \frac{\left(N_{b}-1\right)\left(N_{b}-2\right) \cdots\left(N_{b}-h+1\right)}{(h-1) !} \alpha^{h-1}(1-\alpha)^{N_{b}-h}+\ldots \\
\\
\quad \ldots+\left(1-\frac{I}{I}\right) \frac{\left(N_{b}-1\right)\left(N_{b}-2\right) \cdots\left(N_{b}-I+1\right)}{(I-1) !} \alpha^{I-1}(1-\alpha)^{N_{b}-I} .
\end{aligned}
$$

Notice that the $h$-th term in the above expression, which I denote as $\eta_{2}^{m}[h]$, is the $(h-1)$-th order multi-nominal, and hence can be rearranged with a sequence of coefficients $\left\{c_{i}\right\}_{i=0}^{h-1} \subset \mathcal{R}$ as follows:

$$
\begin{aligned}
\eta_{2}^{m}[h] & =\frac{\left(1-\frac{I}{h}\right)}{(h-1) !} \alpha^{h-1}(1-\alpha)^{N_{b}-h}\left(N_{b}-1\right)\left(N_{b}-2\right) \cdots\left(N_{b}-h+1\right) \\
& =\frac{\left(1-\frac{I}{h}\right)}{(h-1) !} \alpha^{h-1}(1-\alpha)^{N_{b}-h}\left(c_{0} N_{b}^{h-1}+c_{1} N_{b}^{h-2}+\ldots+c_{h-2} N_{b}+c_{h-1}\right) \\
& =\frac{\left(1-\frac{I}{h}\right)}{(h-1) !}\left(N_{b} \alpha\right)^{h-1}(1-\alpha)^{N_{b}-h}\left(c_{0}+c_{1} N_{b}^{-1}+\ldots+c_{h-2} N_{b}^{-h}+c_{h-1} N_{b}^{-h+1}\right) .
\end{aligned}
$$


In this expression, $c_{0}=1$, and $\lim (1-\alpha)^{N_{b}-h}=\lim \left(1-\frac{N_{b} \alpha}{N_{b}}\right)^{N_{b}-h}=e^{-x}$ where $x=\lim N_{b} \alpha$ as already defined. Hence, it is clear from the last equality that this series can be approximated in the limit as follows:

$$
\lim \eta_{2}^{m}[h]=\frac{\left(1-\frac{I}{h}\right)}{(h-1) !} x^{h-1} e^{-x}
$$

This manipulation is allowed as $I$ (over which $h$ is summated) is finite. The same approximation applies to the other terms with $h=\{1,1,2, \ldots, I\}$. By summing up all these approximated terms over $h$, I obtain the following limit expression.

$$
\begin{aligned}
\lim \eta_{2}^{m}=\sum_{h=1}^{I} \lim \eta_{2}^{m}[h] & =\sum_{h=1}^{I} \frac{x^{h-1} e^{-x}}{(h-1) !}-\sum_{h=1}^{I} \frac{I}{h} \frac{x^{h-1} e^{-x}}{(h-1) !} \\
& =\sum_{j=0}^{I-1} \frac{x^{j} e^{-x}}{j !}-I \sum_{j=0}^{I-1} \frac{x^{j} e^{-x}}{(j+1) !} \\
& =\frac{\Gamma(I, x)}{\Gamma(I)}-\frac{I}{x}\left(\frac{\Gamma(I+1, x)}{\Gamma(I+1)}-e^{-x}\right),
\end{aligned}
$$

where I set $j=h-1$. How to obtain the forth equality above has been explained in the proof of Lemma 1. These limiting terms are summated to yield the result:

$$
\lim \eta^{m}=\lim \eta_{1}^{m}+\lim \eta_{2}^{m}=\frac{\Gamma(I, x)}{\Gamma(I)}+\frac{I}{x}\left(1-\frac{\Gamma(I+1, x)}{\Gamma(I+1)}\right) .
$$

QED

\subsection{Complementary Proof of Proposition 5, 8}

The objective of this complementary proof is provide interested (or suspicious) readers with the proof of [Property T] that is used in the proof of Proposition 5, 8.

$$
[\text { Property } \mathrm{T}] \quad \frac{\Gamma(I, x)}{\Gamma(I)} \rightarrow D \text { as } I \rightarrow \infty
$$

where $0 \leq D \leq 1$, and $D=1$ iff $x<I$ and $D=0$ iff $x>I$. This property is well established in the special function literature (see Temme (1996) p.285) and it can be proved as bellow.

The proof follows from a uniform asymptotic expansion of the incomplete gamma function obtained in Temme $(1975,1979)$ : For any $x \geq 0$,

$$
q \equiv \frac{\Gamma(I, x)}{\Gamma(I)}=\frac{1}{2} \operatorname{erfc}(\xi \sqrt{I / 2})+R_{I}(\xi)
$$

where

$$
\xi=(\lambda-1) \sqrt{\frac{2(\lambda-1-\ln \lambda)}{(\lambda-1)^{2}}} ; \quad \lambda=\frac{x}{I} ; \quad \operatorname{erfc}(v)=\frac{2}{\sqrt{\pi}} \int_{v}^{\infty} e^{-t^{2}} d t
$$

with $\operatorname{erfc}(0)=1, \operatorname{erfc}(+\infty)=0$ and $\operatorname{erfc}(-\infty)=2$. This expression is exact, and the asymptotic representation for the remainder, holding uniformly in $\lambda \geq 0$ for $I \rightarrow \infty$, is given as: $R_{I}(\xi)=$ $O\left(I^{-1 / 2} e^{-I \xi^{2} / 2}\right)$ as $I \rightarrow \infty$ (see Temme (1996) p.245).

Suppose now $x<I$. Then, $\lambda<1$ and $\xi<0$. This implies in the limit that:

$$
\xi \sqrt{I / 2} \rightarrow-\infty \text { and } \xi^{2} I / 2 \rightarrow+\infty \text { as } I \rightarrow \infty
$$


which leads to: $\operatorname{erfc}(\xi \sqrt{I / 2}) \rightarrow 2$ and $R_{I}(\cdot) \rightarrow 0$ as $I \rightarrow \infty$. Therefore, $q \rightarrow 1$ as $I \rightarrow \infty$. Further, Since $q \rightarrow 1$ and $I \rightarrow \infty$ imply $R_{I}(\cdot) \rightarrow 0$ and $\xi<0$ as $I \rightarrow \infty$, this proves the first claim: $q \rightarrow 1$ as $I \rightarrow \infty$ iff $x<I$.

Similarly, suppose next that $x>I$. Then, $\lambda>1$ and $\xi>0$, implying:

$$
\xi \sqrt{I / 2} \rightarrow+\infty \text { and } \xi^{2} I / 2 \rightarrow+\infty \text { as } I \rightarrow \infty,
$$

which leads to $\operatorname{erfc}(\xi \sqrt{I / 2}) \rightarrow 0$ and $R_{I}(\cdot) \rightarrow 0$ as $I \rightarrow \infty$. Therefore, $q \rightarrow 0$ as $I \rightarrow \infty$. Further, since $q \rightarrow 0$ and $I \rightarrow \infty$ imply $R_{I}(\cdot) \rightarrow 0$ and $\xi>0$ as $I \rightarrow \infty$, this proves the second claim: $q \rightarrow 0$ as $I \rightarrow \infty$ iff $x>I$. QED

\subsection{Proof of Proposition 9}

The proof is a straightforward application of Proposition 8. As mentioned in the main text, equations (14),(15) imply that: $x_{m} \rightarrow \infty$ and $I \rightarrow \infty$ as $M \rightarrow 0$, and $x_{m} \geq I$ if $S \leq 1$. Keeping this in mind, the claim can be shown by applying [Property $\mathrm{T}]$. There are three cases.

Case $1(S>1): \quad p_{m} \rightarrow 0, \quad \eta^{m} \rightarrow 1,0<Q^{m} / I<1$ as $M \rightarrow 0$.

Proof of Case 1. Given that $I \rightarrow \infty$ as $M \rightarrow 0$, and $x_{m}<I$, [Property T] implies:

$$
\frac{\Gamma\left(I, x_{m}\right)}{\Gamma(I)} \rightarrow 1 \text { and } 1-\frac{\Gamma\left(I+1, x_{m}\right)}{\Gamma(I+1)} \rightarrow 0 \quad \text { as } \quad M \rightarrow 0 .
$$

As shown in the proof of Proposition 8, this implies $\eta^{m} \rightarrow 1$ and $p_{m} \rightarrow 0$ as $M \rightarrow 0$ and hence implies $Q^{m} \rightarrow x_{m}$ as $M \rightarrow 0$. This completes the proof of Case 1 .

Case $2(S<1): \quad p_{m} \rightarrow 1, \quad 0<\eta^{m}<1 \quad Q^{m} / I \rightarrow 1$ as $M \rightarrow 0$.

Proof of Case 2. Given that $I \rightarrow \infty$ and $x_{m}>I$ as $M \rightarrow 0$, [Property T] implies:

$$
\frac{\Gamma\left(I, x_{m}\right)}{\Gamma(I)} \rightarrow 0 \text { and } 1-\frac{\Gamma\left(I+1, x_{m}\right)}{\Gamma(I+1)} \rightarrow 1 \quad \text { as } \quad M \rightarrow 0,
$$

which further imply that: $\eta^{m} \rightarrow I / x_{m}=S<1$ as $M \rightarrow 0$ and hence $Q^{m} / I=x^{m} \eta^{m} / I \rightarrow 1$ as $M \rightarrow 0$. Applying these limiting values into equation (10) yields: $p_{m} \rightarrow 1$ as $M \rightarrow 0$. This completes the proof of Case 2 .

Case $3(S=1): \quad 0<p_{m}<1, \quad \eta^{m} \rightarrow 1 \quad Q^{m} / I \rightarrow 1$ as $M \rightarrow 0$.

Proof of Case 3. Given that $I \rightarrow \infty$ and $x_{m}=I$ as $M \rightarrow 0$, [Property T] implies:

$$
\frac{\Gamma\left(I, x_{m}\right)}{\Gamma(I)} \rightarrow D \text { and } 1-\frac{\Gamma\left(I+1, x_{m}\right)}{\Gamma(I+1)} \rightarrow 1-D \quad \text { as } \quad M \rightarrow 0,
$$

where $0<D<1$. Given $x_{m}=I$, this further implies that: $\eta^{m} \rightarrow 1$ as $M \rightarrow 0$ and hence $Q^{m} / I=x^{m} \eta^{m} / I \rightarrow 1$ as $M \rightarrow 0$. Applying these limiting values into equation (10) yields: $0<p_{m}<1$ as $M \rightarrow 0$. This completes the proof of Case 3. QED 


\section{References}

[1] Acemoglu, D., and R. Shimer (1999a), Efficient Unemployment Insurance, Journal of Political Economy, 107, 893-928.

[2] Acemoglu, D., and R. Shimer (1999b), Holdups and Efficiency with Search Frictions, International Economic Review, 40, 827-849.

[3] Aguirregabiria, V. (1999), The Dynamics of Markups and Inventories in Retailing Firms, Review of Economic Studies, ,66, 275-308.

[4] Aguirregabiria, V. (2003), Strategic Stockouts in Supermarkets, Boston University manuscript.

[5] Albrecht, J., P. Gautier, S. Tan, and S. Vroman (2003), Matching with Multiple Applications Revisted, forthcoming in Economics Letters.

[6] Andersen Consulting (1996), Where to Look for Incremental Sales Gains: The Retail Problem of Out-of-Stock Merchandise, The Coca-Cola Retailing Research Council.

[7] Basker, E. (2005), Selling a Cheaper Mousetrap: Wal-Mart's Effect on Retail Prices, Journal of Urban Economics, 58, 203-229

[8] Biglaiser, G. (1993), Middlemen as Experts, RAND Journal of Economics, 24, 212-223.

[9] Burdett, K., S. Shi, and R. Wright (2001), Pricing and Matching with Frictions, Journal of Political Economy, 109, 1060-85.

[10] Burstein, A.T, J.C. Neves, and S. Rebelo (2003), Distribution Costs and Real Exchange Dynamics during Exchange-rate-based-stabilizations, Journal of Monetary Economics, 50, 1189-1214.

[11] Butters, G. (1977), Equilibrium Distribution of Sales and Advertising Prices, Review of Economic Studies, 44, 465-491.

[12] Caillaud, B. and B. Jullien (2003), Chicken and Egg: Competition among Intermediation Service Providers, RAND Journal of Economics 34, 521-552.

[13] Chevalier, J.A. (1995), Do LBO Supermarkets Charge More? An Empirical Analysis of the Effects of the LBOs on Supermarket Pricing, Journal of Finance 50, 1095-1112.

[14] Clower, R. and A. Leijonhufvud (1975), The Coordination of Economic Activities: A Keynesian Perspective, American Economic Review 65, 182-188.

[15] Coles, M., and J. Eeckhout (2003), Indeterminancy and Directed Search, Journal of Economic Theory 111, 265-276.

[16] Corbae, D., T. Temzelides, and R. Wright (2003), Directed Matching and Monetary Exchange, Econometrica 71, 731-756.

[17] De Fraja, G., and J. Sakovics, (2001), Warlas Retrouve: Decentralized Trading Mechanisms and the Competitive Price, Journal of Political Economy, 109, pp.842-863.

[18] Diamond, P. A., (1971), Model of Price Adjustment, Journal of Economic Theory, 3, 156-168.

[19] Faig, M., and B. Jerez (2005), A Theory of Commerce, Journal of Economic Theory, 22, 60-99.

[20] Gehrig, T. (1993), Intermediation in Search Markets, Journal of Economics and Management Strategy 2-1, 97-120.

[21] Hendershott, T., and J. Zhang (2003), A Model of Direct and Intermediated Sales, University of California, Berkeley manuscript. 
[22] Hosios, A.J. (1990), On the Efficiency of Matching and Related Models of Search and Unemployment, Review of Economic Studies, 57, 279-298.

[23] Johri, A. and J. Leach (2002), Middlemen and Allocation of Heterogeneous Goods, International Economic Review 43, 347-361.

[24] Lagos, R. and R. Wright (2005), A Unified Framework for Monetary Theory and Policy Analysis, Journal of Political Economy, 113, 463-484.

[25] Li, Y. (1998), Middlemen and Private Information, Journal of Monetary Economics, 42, 131-159.

[26] Masters, A. (2004), Middlemen in Search Equilibrium, SUNY Albany manuscript.

[27] Moen, E. (1997), Competitive Search Equilibrium, Journal of Political Economy, 105, 385-411.

[28] Montgomery, J. (1991) Equilibrium Wage Dispersion and Interindustry Wage Differentials, Quarterly Journal of Economics, 106, 163-179.

[29] Mortensen, D., and R. Wright (2002), Competitive Pricing and Efficiency in Search Equilibrium, International Economic Review, 43, 1-20.

[30] Peters, M. (1991), Ex-Ante Price Offers in Matching Games : Non-Steady States, Econometrica, $59,1425-1454$.

[31] Rochet, J-C. and J. Tirole (2004), Two-Sided Markets : An Overview," IDEI Working Paper, Toulousse, France.

[32] Rocheteau, G., and R. Wright. (2005), Money in Search Equilibrium, in Competitive Equilibrium, and in Competitive Search Equilibrium, Econometrica, 73, 175-202.

[33] Rubinstein, A., and A. Wolinsky. (1987), Middlemen, Quarterly Journal of Economics 102, 581593.

[34] Rust, J., and R., Hall. (2003), Middlemen versus Market Makers: A Theory of Competitive Exchange, Journal of Political Economy, 111, 353-403.

[35] Shevichenko, A. (2004), Middlemen, International Economic Review 45, 1-24.

[36] Shi, S. (2002a) Product Market and the Size-Wage Differential, International Economic Review, $43,21-54$.

[37] Shi, S. (2002b) A Directed-Search Model of Inequality with Heterogeneous Skills and Skill-Biased Technology, Review of Economic Studies, 69, 467-491.

[38] Shimer, R. (1996), Essays in Search Theory, PhD dissertation, Massachusetts Institute of Technology: Cambridge, Massachusetts.

[39] Shimer, R. (2005), The Assignment of Workers to Jobs in an Economy with Coordination Frictions, Journal of Political Economy, 113, 996-1025.

[40] Smith, E. (2002), Intermediated Search, forthcoming in Economica.

[41] Spulber, D.F. (1996), Market Making by Price Setting Firms, Review of Economic Studies 63, $559-80$.

[42] Spulber, D.F. (1999), Market Microstructure, Cambridge.

[43] Taylor, H. and S. Karlin (1998) An Introduction to Stochastic Modeling. Academic Press, third edn.

[44] Temme, N.M. (1975), Uniform Asymptotic Expansions of the Incomplete Gamma Functions and the Incomplete Beta Functions, Mathematics of Computation 29, 1109-1114. 
[45] Temme, N.M. (1979), The Asymptotic Expansion of the Incomplete Gamma Functions, SIAM Journal on Mathematical Annalysis 10, 757-766.

[46] Temme, N.M. (1996), Special Functions: An Introduction to the Classical Functions of Mathematical Physics. Wiley, New York. 